\title{
LA MODIFICACIÓN DE LA NORMATIVA AMBIENTAL APLICABLE A UN PROYECTO QUE CUENTA CON UNA RESOLUCIÓN DE CALIFICACIÓN AMBIENTAL
}

THE MODIFICATION OF THE ENVIRONMENTAL REGULATION APPLICABLE TO A PROJECT THAT HAS AN EXISTING ENVIRONMENTAL PERMIT (RCA)

\begin{tabular}{|c|c|}
\hline \multicolumn{2}{|c|}{ ARTÍCULO INÉDITO DE INVESTIGACIÓN } \\
\hline CÓMO CITAR ESTE ARTÍCULO (CHICAGO) &  \\
\hline \multirow[t]{2}{*}{ REVISTA DE DERECHO APLICADO LLM UC } & $\begin{array}{l}\text { Número } 3 \\
\text { Julio } 2019 \\
\text { ISSN: } 245^{2-4} 344\end{array}$ \\
\hline & $\begin{array}{l}\text { Recepción: io de abril, 2or9 } \\
\text { Aceptación: II de julio, 20I9 }\end{array}$ \\
\hline
\end{tabular}




\section{Resumen}

El presente análisis tiene por objeto dilucidar si la pérdida de vigencia de una norma que forma parte del contenido de una autorización de funcionamiento, mediante su inclusión como cláusula iuris, comunica algún efecto a este último, ya sea incidiendo en su validez o instando a su modificación para encontrar la debida cobertura en otra norma jurídica. Lo anterior, por cuanto se plantea que el contenido de este tipo de actos administrativos, no sólo estará en contradicción con la normativa aplicable a dicho acto administrativo, sino que esta inconformidad podrá también verificarse a futuro. En particular, se revisa el caso de la Resolución de Calificación Ambiental (RCA), que, en atención a su capacidad de regular indefinidamente un proyecto o actividad, despliega sus efectos en el tiempo en paralelo a su permanencia en el mundo jurídico, requiriéndose en consecuencia, su adecuación con la normativa ambiental aplicable durante toda su vigencia.

Palabras clave: RCA, contenido del acto administrativo, cambio normativo, interés público, actualización acto administrativo

\section{Abstract}

The purpose of the following analysis is to identify if the loss of validity of a regulation contained within an enforced authorization as a iuris clause effects a change on it, either affecting its validity or pushing for its modification in order to find adequate legal coverage in a different norm. Should the aforementioned situation occur, the content of this type of administrative acts will not only be in contradiction with the applicable regulation, but in addition, such a contradiction might also be verified in the future. We particularly focus on the case of the RCA environmental permit, which, due to its ability to regulate a project or activity indefinitely, displays its effects

over time in parallel with its permanence in the legal world, thus requiring compliance with environmental regulations applicable throughout its validity.

Keywords: RCA, subject of the administrative act, regulatory change, public interest, update of administrative act 


\section{Doris Sepúlveda Solar}

Universidad de Chile

Magíster (c) en Derecho Público

Santiago, Chile

sepulveda.doris@gmail.com

Universidad de Chile

Master (c) in Public Law

Santiago, Chile

sepulveda.doris@gmail.com
Doris Sepúlveda Solar estudió Derecho en la Universidad de Chile y es candidata a Magíster en Derecho Público en dicha casa de estudios. Ejerce el derecho a partir de 2008, especializándose en Derecho Ambiental y Administrativo, trabajando en temas de regulación y recursos naturales. Es autora del libro Invalidación sobreviniente. El caso de la resolución de calificación ambiental (Abeledo Perrot, 2012) y del artículo "La facultad de revisión de la Resolución de Calificación Ambiental y la existencia de una potestad de invalidación implícita" (Revista de Derecho Administrativo 6).

Doris Sepúlveda Solar studied Law at the Universidad de Chile and is a candidate for a master's degree in Public Law at the same institution. She practices from 2008, specializing in Environmental and Administrative Law, working on issues regarding regulation and natural resources. She is the author of the book Invalidación sobreviniente. El caso de la resolución de calificación ambiental (Abeledo Perrot, 2012) and of the article "La facultad de revisión de la Resolución de Calificación Ambiental y la existencia de una potestad de invalidación implícita" (Revista de Derecho Administrativo 6). 


\section{La modificación de la normativa que forma parte del contenido de la RCA}

Con anterioridad a la Ley $\mathrm{N}^{\circ} 20.417$, que vino a zanjar a nivel legal la naturaleza jurídica de la Resolución de Calificación Ambiental (RCA) mediante la incorporación del concepto de "autorización de funcionamiento" en el texto de la Ley Orgánica de la Superintendencia del Medio Ambiente ${ }^{1}$, nuestra doctrina nacional ya la caracterizaba como un acto administrativo que ligaba a su titular con la Administración de forma permanente ${ }^{2}$. Esto implicó ir dejando de lado poco a poco el tópico sobre su intangibilidad, atendido su supuesto carácter de acto declarativo de derechos ${ }^{3}$.

Aun cuando la ejecución del proyecto, conforme a lo autorizado por la RCA, constituye para el titular una manifestación de su derecho a desarrollar una actividad económica lícita - garantizado por la Constitución Política de la Republica en su artículo 19 n 21- lo cierto es que el carácter declarativo de la RCA resulta lógico en el contexto de un sistema de calificación ambiental reglado. Sin embargo, éste no sería el caso de un contexto donde se le reconocen a la Administración amplias facultades valorativas para fijar los límites y condiciones de ejercicio de la actividad mediante la posibilidad de condicionar el acto autorizatorio, imponer cargas accesorias y, en general, de darle un carácter creativo al mismo, evidenciando con ello hasta qué punto difiere la posición del titular del proyecto antes y después del otorgamiento de la respectiva $\mathrm{RCA}^{4}$.

Precisamente, en la RCA es posible distinguir cláusulas que son una reiteración de exigencias normativas, también denominadas clausulas iuris, cláusulas que concretan exigencias

1 Artículo $3^{\circ}$, letras g), h) y p) de la Ley Orgánica de la Superintendencia del Medio Ambiente, cuyo texto fue fijado en el Artículo $2^{\circ}$ de la Ley $20.4 \mathrm{I} 7$.

2 Mario Galindo Villarroel, "Concepto de la RCA y jurisprudencia relacionada" (seminario, Universidad de los Andes, 2006).

3 En dicho sentido, el profesor Arturo Fermandois, plantea que "El mero cambio en las circunstancias de hecho no es suficiente, ni podría serlo, para hacer desaparecer el acto que ha constituido lícitamente derechos en el administrado", y que "si la invalidación se pretende por motivos de mera oportunidad, entonces desaparece la invalidación y nos trasladamos en rigor al plano de la revocación, la que aparece expresamente prohibida por el artículo 6 ${ }^{\circ}$ de la propia Ley $N^{\circ}$ I9.880". Arturo Fermandois, "Invalidación Administrativa y caso Celco: estabilidad o precariedad de los permisos ambientales", en Sentencias Destacadas 2005 (Santiago: Libertad y Desarrollo, 2005), 26.

4 Así, la autorización ambiental no es un simple acto declarativo de un derecho preexistente, sino que se trata más bien de un acto constitutivo, en tanto que creador de una relación jurídica estable y duradera entre la Administración y el autorizado. Marcelo Mardones Osorio y Nicolás Cannoni Mandujano, "Caducidad de la Resolución de Calificación Ambiental y Reglamento del SEIA", Revista Chilena de Derecho $43, \mathrm{n}^{\circ} 2$ (20I6): $5^{8 \mathrm{I}}$. 
genéricamente previstas en la normativa y cláusulas que incorporan reglas de ejercicio de la actividad que no vienen impuestas por la normativa ${ }^{5}$.

Al respecto, se plantea que las cláusulas iuris en sí mismas no tienen contenido decisorio, pues, al incorporarse al acto, no hacen sino reproducir lo que la norma ya dispone ${ }^{6}$. Estas cláusulas son iuris, es decir provienen inmediatamente de la norma, no de la Administración, y no determinan por sí mismas ninguna consecuencia jurídica ${ }^{7}$, ya que no modifican la posición jurídica del particular: ni amplían, ni reducen sus derechos ${ }^{8}$.

Ahora bien, cabe tener en cuenta que, con frecuencia, las normas definen el ejercicio lícito de la actividad en base a criterios genéricos, más o menos determinados; remiten a umbrales límite o exigen la adopción de determinadas medidas que han de especificarse después para cada actuación. En este contexto se le encomienda a la Administración la concreción de dichos parámetros con ocasión del otorgamiento de la autorización, lo cual conduce al territorio pantanoso de los conceptos normativos indeterminados ${ }^{9}$

Es por ello que se discute si en dichos casos se está propiamente ante cláusulas iuris o si se trata de cláusulas accesorias ${ }^{10}$, por cuanto la aplicación de la norma deja un no despreciable margen de apreciación a la administración, que ha de definir en cada caso las condiciones de compatibilidad de la actividad. En la práctica, la concreción en cada autorización de cláusulas vagamente definidas en la normativa no puede decirse que carezca de contenido decisorio (discrecionalidad cognitiva) ${ }^{11}$. Por el contrario, en esa integración o concreción hay ponderación y valoración administrativa ${ }^{12}$.

En dicho sentido, los artículos 12 letra g) y 12 bis letra c) de la Ley $\mathrm{N}^{\circ} 19.300$, Sobre Bases Generales del Medio Amiente (LBGMA), exigen al proponente del respectivo proyecto un plan de cumplimiento de la legislación ambiental aplicable o la indicación de la normativa

5 José Carlos Laguna De Paz, La autorización administrativa (Madrid: Civitas-Thomson Reuters, 2006), 217-2I9.

6 Ibid.,2I7.

7 Francisco Velasco Caballero, Las cláusulas accesorias del acto administrativo (Madrid: Tecnos, I996), 59-6o.

8 Ver supra nota 5, 2I7.

9 Ver supra nota 5, 2I8-2i9.

10 El contener o no decisión administrativa es lo que distingue, pues, la cláusula accesoria de la cláusula iuris. Ver supra nota 7,62 .

11 Ver supra nota 5, 219.

12 Ver supra nota 7, 210. 
ambiental aplicable, dependiendo del instrumento de evaluación presentado, esto es, un Estudio de Impacto Ambiental (EIA) o una Declaración de Impacto Ambiental (DIA). Ello abarcará normas de distintas clases y rangos (leyes, decretos supremos, resoluciones administrativas y normas técnicas), todas de carácter ambiental. En tanto, conforme a la letra d.1. del artículo 60 del Decreto Supremo N 40 de 2012, del Ministerio del Medio Ambiente, que establece el Reglamento del Sistema de Evaluación de Impacto Ambiental (RSEIA), se exige dentro del contenido de una RCA aprobatoria el señalamiento de las normas a las cuales deberá ajustarse la ejecución del proyecto o actividad.

Esta remisión a la normativa en cuestión o la reiteración de las obligaciones contenidas en dicha normativa, además de tender a la simplificación de la extensión del texto del acto autorizatorio, constituyen a todas luces cláusulas iuris que no son más que el reflejo de un marco jurídico que descansa en un modelo de intervención administrativa de ventanilla única, que implica anexar y aglutinar a una resolución final, en este caso la RCA, una serie de permisos ambientales sectoriales y, consecuentemente, la normativa ambiental sectorial que sirve de fundamento a dichos pronunciamientos ${ }^{13}$.

De esta forma, es posible estimar que la RCA corresponde al cauce para que se aplique al titular de un proyecto la normativa ambiental que corresponde al mismo, por cuanto en ella convergerán los distintos estatutos sectoriales de carácter ambiental, ya sea mediante una mera enunciación de las normas que regirán la respectiva actividad, o mediante la repetición completa o parcial del texto normativo objeto de la remisión. Cuando la autoridad ambiental hace uso de las remisiones normativas, lo que está haciendo es regular determinada materia por referencia a una norma jurídica, de tal forma que aquélla queda incorporada en el contenido de la RCA.

Además de este clausulado que se remitirá al ordenamiento jurídico existente, los artículos 12 letra g) y 12 bis letra c) de la LBGMA exigen especificar la forma en que se dará cumplimiento a dicha normativa en el caso concreto, cuestión que a nivel reglamentario también es exigida en los artículos 18 letra 1) y 19 letra c) del RSEIA. Lo anterior conlleva para el titular la elaboración de una propuesta que contendrá una serie de acciones cuya implementación tendrá por objetivo dar cumplimiento a la normativa aplicable. De esta forma, las cláusulas iuris tendrán un correlato discrecional, por cuanto la definición de la forma en que se dará cumplimiento a la normativa aplicable no sólo conllevará un ejer-

13 Destacamos el matiz del SEIA como una instancia de regulación de la actividad o proyecto de que se trate. En efecto, muy distinto es estar sujeto a las prescripciones generales contenidas en la normativa ambiental que tener que cumplir las obligaciones y compromisos concretos contenidos en una RCA. Alberto Barros Bordeu, "Regulación y discrecionalidad en el sistema de evaluación de impacto ambiental: el procedimiento administrativo como garantía procedimental" (tesis de pregrado, Universidad de Chile, 2009), 26. 
cicio cognitivo de interpretación del precepto normativo, sino que derechamente dejará un margen de discreción o de apreciación subjetiva a la administración, quien finalmente determinará si dicho plan de cumplimiento, en los términos presentados, podrá conformar el contenido de la RCA.

Cabe indicar que, en paralelo a la determinación de las normas ambientales aplicables a un determinado proyecto y a la forma en que se dará cumplimiento a las mismas, la RCA contempla la inclusión de cláusulas que reflejan el ejercicio de potestades derechamente discrecionales, referidas a la imposición de condiciones técnicas conforme lo dispone el artículo 25 de la LBGMA y a la definición de medidas de mitigación, compensación o reparación apropiadas para hacerse cargo de los impactos ambientales del proyecto, de acuerdo a lo dispuesto en el artículo 16 de la LBGMA.

De esta forma, las cláusulas contenidas en la RCA no pueden ser consideradas como condiciones estrictamente regladas, por cuanto en su determinación interviene en mayor o menor grado la autoridad ambiental, quedando el régimen jurídico de la actividad crecientemente determinado por la propia autorización.

Es relevante tener en cuenta que este contenido de carácter mixto de la RCA se encuentra expresamente reconocido en el artículo 9 bis de la LBGMA y en el artículo 59 del RSEIA, los cuales, al referirse al carácter vinculante para la decisión final de los aspectos normados en la legislación ambiental vigente - además de evidenciar que la normativa ambiental aplicable forma parte del contenido típico de dicho acto autorizatorio por constituir un requisito esencial para su otorgamiento - llevan a distinguir entre un contenido reglado y otro discrecional, toda vez que los aspectos normados se definen como «[...] aquellas materias regladas en sus supuestos y resultados, de manera que exista una sola consecuencia jurídica. De este modo, no constituyen aspectos normados aquellos asuntos sujetos a discrecionalidad en la evaluación».

Ahora bien, considerando la aptitud de la RCA para regular un proyecto por todo el período que conlleve su ejecución y el hecho de que las obligaciones que se imponen a su titular no derivan exclusivamente de su contenido discrecional, sino también de la normativa de carácter ambiental a que se le somete en virtud del establecimiento de cláusulas iuris, se hace necesario determinar si la situación de hecho regulada originalmente por la RCA puede mantenerse ante el escenario de un cambio normativo (entendido éste como una circunstancia sobreviniente que puede enfrentar el acto administrativo) o, por el contrario, si deberá adaptarse a la nueva normativa, y de ser así, cómo deberá llevarse a cabo dicha adaptación.

Ello por cuanto la entrada en vigencia de una nueva norma conllevará la sustitución de algunas de las disposiciones de una norma anterior o derechamente de toda la norma anterior reguladora de la materia de que se trate, es decir, involucrará necesariamente un 
efecto derogatorio en virtud del cual las normas derogadas pierden la fuerza para regular los supuestos de hecho a que ellas mismas se refieren ${ }^{14}$.

Al respecto, habitualmente se plantea que, atendida la naturaleza jurídica de la RCA como una autorización de funcionamiento, la adaptación a la nueva normativa ambiental se verificaría de forma automática ${ }^{15}$, o que aquella determinación se reduciría a un problema interpretativo cuya solución debe propender a ajustarse al principio preventivo ${ }^{16}$.

14 La esencia del efecto derogatorio radicaría en que la ley derogada deja de surtir los efectos propios de toda ley: pierde la fuerza para regular los supuestos de hecho a que ella misma se refiere. Luis María Díez-Picazo, La derogación de las leyes. (Madrid: Civitas, I99o), i6r.

15 Como se puede apreciar, tanto en la Declaración como en el Estudio de Impacto Ambiental se requieren acreditar el cumplimiento de la normativa ambiental vigente, así como los requisitos ambientales aplicables al proyecto. Por lo tanto, el titular siempre debe ajustar el desarrollo de su proyecto al cumplimiento de las normas vigentes, aunque con posterioridad a la aprobación del proyecto se vaya modificando la normativa o promulgándose nuevas normas. En tal sentido la aprobación del proyecto no es estática o inmodificable, sino que en la medida que evoluciona la normativa se debe ir constantemente adaptando al cumplimiento de aquella. Juan Ignacio Urrutia Cáceres, "El impacto ambiental no previsto en el marco del Sistema de Evaluación de Impacto Ambiental" (tesis de magíster, Universidad de Chile, 2009), I $47 \cdot$ ¿Qué ocurre si una RCA establece límites que luego son modificados por una ley o norma reglamentaria de aplicación general? El SEIA es un instrumento preventivo que determina si el impacto ambiental se ajusta a la legislación vigente del momento. Si esa legislación se modifica, necesariamente debe modificarse de pleno Derecho la RCA. Lo anterior es también una consecuencia de una característica propia del Derecho Ambiental: el Conocimiento Progresivo. Felipe Guzmán, "Algunos aspectos de la relación entre la RCA y normativa vigente" (seminario, Universidad de los Andes, 2006).

16 Adicionalmente, entre muchos otros cambios, ocurre que ciertas normas legales y administrativas son modificadas. En iguales circunstancias, las autoridades de turno y las políticas y planes públicos a nivel nacional y regional sufren cambios. Esto lleva, naturalmente, a que los proyectos deban, al margen de su texto expreso, adecuarse a nuevos escenarios. Contextos que al margen de su dimensión jurídica, política, social y económica, obligan a proyectos o actividades pensadas para varias décadas a incorporar parte de dicho acervo en su realización, control y cumplimiento. En consecuencia, cambios en el sistema ambiental obligan, al momento de interpretar una RCA, a incorporar, dentro de dicho análisis, las alteraciones que el entorno ha tenido, todo con la finalidad de arribar a una solución razonable, proporcional y ajustada plenamente al principio preventivo que inspira a éste y otros instrumentos de gestión ambiental que la ley reconoce en base a la tipología propia de cada proyecto o actividad. Edesio Carrasco Quiroga y Javier Herrera Valverde, "La interpretación de la Resolución de Calificación Ambiental”, Revista Chilena de Derecho $4_{4} \mathrm{I}_{1} \mathrm{n}^{\circ} 2$ (20I) $)$ : 66r. 
Lo anterior, si bien podría llegar a ser admisible en lo que se refiere a la verificación del cumplimiento de límites de emisión al constituir su aplicación un ejercicio simple para cualquier operador jurídico ${ }^{17}$, lo cierto es que, tratándose de aquellas condiciones establecidas en la respectiva RCA para dar cumplimiento a la normativa ambiental -las cuales muchas veces involucran determinadas obras o la adopción de una forma específica de operación-, la verificación de su compatibilidad con la nueva norma no será automática, sino que requerirá de una actividad cognitiva, más o menos compleja, que permita comprobar su idoneidad y aptitud para cumplir esta vez con el nuevo estándar ambiental ${ }^{18}$.

Por lo mismo, en pro de la certeza del contenido de la RCA, en algunas ocasiones los titulares han optado por someter a conocimiento de la autoridad la adaptación del proyecto conforme a la nueva norma ambiental mediante consultas de pertinencia de ingreso al SEIA, para efectos de determinar si los cambios que ésta conlleva constituyen o no una modificación del proyecto que amerite su evaluación ambiental según lo dispuesto en el artículo 2 letra g) del RSEIA. Aun cuando el cambio normativo no es un criterio o supuesto que per se permita determinar si se está en presencia de una modificación de proyecto en los términos establecidos en el RSEIA, toda vez que - como bien se explicará más adelante- éste incide en el contenido de la autorización y no en el proyecto mismo, lo cierto es que la consulta de pertinencia asociada a una adaptación de proyecto producto de un cambio normativo, indirectamente permitirá comprobar si los ajustes incorporados al proyecto se condicen con la respectiva normativa.

Sin embargo, esta forma de proceder no es la regla general, toda vez que la consulta de pertinencia posee un carácter voluntario, dependiendo su utilización exclusivamente de

17 Ejemplo de ello lo constituyen los procesos sancionatorios Roles F-०34-20I6 y D-००4-20I7, en donde a propósito del incumplimiento de normas, condiciones y medidas de una RCA, conforme al artículo 35, letra a) de la LOSMA, la Superintendencia del Medio Ambiental ha imputado también como normativa infringida el D.S. $n^{\circ} 3^{8}$, de 201 , del Ministerio del Medio Ambiente, en circunstancias que solo el D.S. n 146 $_{6}$, de 1997 , del Ministerio Secretaría General de la Presidencia, era la norma que formaba parte del contenido de la respectiva RCA.

18 La determinación de la normativa aplicable a un proyecto determinado resulta, en los hechos, ser una tarea mucho más difícil de lo que aparenta. En ese sentido, sin perjuicio de que una fracción de la normativa sectorial esté configurada sobre la base de parámetros concretos y de fácil determinación como, por ejemplo, el respeto a las disposiciones urbanísticas, la evaluación ambiental debe pronunciarse también respecto de materias que no se encuentran regladas o que, encontrándose tal, padecen de un alto grado de indeterminación. De esta manera, en materia ambiental las normas están configuradas a menudo por conceptos jurídicos indeterminados, conceptos normativos e incluso materias que dejan entregada en la apreciación discrecional de la Administración del Estado la posibilidad de realizar una acción concreta. Barros Bordeu, "Regulación y discrecionalidad en el sistema de evaluación de impacto ambiental" (tesis de pregrado, Universidad de Chile, 2009), I2. 
la iniciativa del titular del proyecto. Por otra parte, este mecanismo presenta limitaciones, en cuanto posee un ámbito que vendrá determinado por la propuesta que se presente como adaptación del proyecto, en circunstancias en que ésta pudiese abarcar aspectos no considerados por el titular. Las mismas consideraciones resultan aplicables respecto del ingreso al SEIA. Así las cosas, lo que termina ocurriendo, en la práctica, es que los titulares no someten a evaluación ambiental la modificación de sus proyectos producto de un cambio normativo, manteniéndose en consecuencia un contenido desactualizado de la RCA que no se ajusta al ordenamiento vigente. Sin embargo, éstos cumplen en paralelo, desde su propia perspectiva, con lo preceptuado en otros instrumentos de gestión ambiental u otras normativas ambientales. Tal coexistencia de instrumentos ambientales, cuyos contenidos obligatorios difieren entre sí, evidentemente desvirtúa el carácter integrador del SEIA como mecanismo de ventanilla única ${ }^{19}$.

De ahí que mediante el presente trabajo se pretenda evidenciar cómo la modificación de la norma que forma parte del contenido de una RCA incide en la validez de esta última, requiriéndose en consecuencia una decisión administrativa al respecto, que se debiese traducir en la modificación del acto autorizatorio.

\section{El cambio normativo y su incidencia en la validez de la RCA}

Como se pasará a explicar a continuación, el caracterizar a la RCA como una autorización de funcionamiento conlleva consecuencias en lo que respecta al control de legalidad de la misma, pues ésta, durante su periodo de vigencia, podría perder con el transcurso del tiempo la debida correspondencia entre lo dispuesto en la norma atributiva de la potestad de evaluación ambiental y las circunstancias supervinientes. Esto último en lo que se refiere a la comprobación y certificación del cumplimiento de la normativa ambiental para el desarrollo de una determinada actividad, producto del cambio normativo que experimenten aquellas normas que forman parte de su contenido.

Cabe partir planteando que en toda actuación administrativa hay, por decirlo de una manera muy simple, un porqué y un para qué. La administración actúa porque una norma la ha apoderado en ese sentido para que cumpla una finalidad de interés público concreta $^{20}$. En dicho contexto, todo acto se emite para algo; es decir, dándose determinados presupuestos, se forma la voluntad administrativa, constituyendo una decisión en determinado sentido ${ }^{21}$. El ciclo vital del acto administrativo comienza con la existencia de determinadas circunstancias que, ponderadas por la administración, sirven para que

19 Jorge Bermúdez Soto, Fundamentos de Derecho Ambiental (Valparaíso: Ediciones Universitarias de Valparaíso, 20I4), 268.

20 Carmen Chinchilla Marín, La desviación de poder (Madrid: Editorial Civitas, I999), 69.

21 Doris Piccinini García, Teoría del decaimiento de los actos administrativos (Santiago: Editorial Jurídica de Chile, r968), 67. 
ésta decida actuar ${ }^{22}$. De este modo, es posible conceptualizar el presupuesto de hecho como el elemento objetivo de la estructura jurídica del acto administrativo que se hace cargo de la necesaria correlación y coincidencia que deben de concurrir entre la tipicidad del supuesto legal que contempla la norma atributiva de la potestad y las circunstancias materiales del caso concreto.

En dicho sentido, conforme a lo dispuesto en los artículos 16 y 19 de la LBGMA, constituye un presupuesto o requisito de aprobación de un proyecto presentado por medio de un EIA o DIA el cumplimiento de la normativa de carácter ambiental aplicable y el que los antecedentes presentados permitan certificar el cumplimiento de todos los requisitos ambientales aplicables, conforme lo dispone el artículo 24 de la LBGMA.

Ahora bien, examinados dichos presupuestos, la autoridad administrativa obra para alcanzar un objeto, es decir, el efecto del acto jurídico, el resultado práctico que el órgano se propone conseguir a través de su acción y que se traduce en el contenido del acto, el cual, a su vez, debe ser idóneo para la consecución del fin que el acto persigue ${ }^{23}$.

En el caso concreto de la RCA, como bien ya se indicó, su contenido se encuentra regulado por el artículo 60 del RSEIA, el cual dispone que, en el caso de aprobación de un proyecto, se deberán señalar las normas y las condiciones a las cuales deberá ajustarse su ejecución, incluidas aquéllas bajo las cuales se otorgarán los permisos ambientales sectoriales que, de acuerdo con la legislación, deben emitir los órganos de la Administración del Estado; y las medidas de mitigación, compensación y reparación, cuando corresponda, en los casos de los EIA.

Es decir, normativamente se exige configurar el proyecto en conformidad a la normativa vigente a la época del otorgamiento de la RCA, lo que lleva a que dicho acto administrativo se encuentre conformado por explícitas exigencias del ordenamiento jurídico que se incorporan a la autorización en calidad de parte integrante como cláusulas iuris, como ya bien se explicó en el primer apartado de este trabajo, en tanto, en la práctica, dicho contenido implica construir determinadas instalaciones de una forma en particular, incorporar sistemas de control de emisiones u operar de una forma determinada para cumplir con los respectivos límites de emisión o demás restricciones normativas.

Ahora bien, cuando se deroga o modifica la norma que forma parte del contenido de la $\mathrm{RCA}-\mathrm{y}$, consecuentemente, al perder dicha norma total o parcialmente la fuerza para regular los supuestos de hecho a que ella misma se refiere- se produce, en primer término,

22 Adolfo Carretero Pérez, "Causa, motivo y fin del acto administrativo", Revista de Administración Pública $5^{8}$ (I969): $3^{8 .}$

23 Manuel María Diez, El acto administrativo (Buenos Aires: Editora Argentina, r96r), 227-233. 
una pérdida del sustento normativo del acto autorizatorio y, luego, un desajuste o falta de adecuación entre el acto (tal y como surge en un momento determinado a la vida jurídica), de un lado, y el estado normativo (posterior a que la propia evolución del ordenamiento pueda conducir), de otro, en cuanto este último se erige como parámetro de su validez ${ }^{24}$.

Por ello no es admisible que, ante la falta de adecuación sobrevenida entre el contenido del acto y el fin normativamente previsto por el ordenamiento jurídico para dicho tipo de acto, se sigan reconociendo como válidos sus efectos y la mutación de la realidad que estos conllevan, dado que dichos derechos y obligaciones serán necesariamente contrarios a las nuevas normas y, consecuentemente, lesivos para el interés público, toda vez que su contenido responderá a un escenario normativo distinto al que se verificará con posterioridad al cambio. Lo anterior (por cuanto el caso más evidente de mutación del interés público lo representa el cambio normativo ${ }^{25}$ ), toda vez que las nuevas normas son la expresión de un cambio de circunstancias o de una distinta apreciación y ponderación de circunstancias ya existentes, que determinan una reacción activa de modificación del orden jurídico y que implican la formulación de nuevos criterios de apreciación del interés público ${ }^{26}$.

Como bien se ha concluido por algunos autores, nadie puede adquirir legítimamente, y menos a través de un simple instrumento autorizatorio, el derecho a dañar a otro o crear situaciones permanentes de riesgo para terceros ${ }^{27}$. La norma posterior que incide sobre la actividad autorizada no sólo afecta a algo que ya estaba, sino también a algo que está siendo y que debe seguir siendo conforme en todo momento al interés general ${ }^{28}$. Más aun tratándose de materias ambientales, en donde los aspectos que principalmente experi-

24 Una postura semejante mantiene Boquera. Este autor pone de manifiesto que el otorgamiento de las licencias responde siempre a la apreciación de los hechos determinantes que haya llevado a cabo la Administración, de tal forma que existe siempre una relación de adecuación necesaria entre el contenido, los efectos del acto y esos hechos determinantes. Por ello, si las circunstancias que se tuvieron en cuenta para el otorgamiento desaparecen o cambian, ello lleva consigo la desaparición de un elemento esencial del acto o, al menos, la ruptura de la necesaria adecuación entre los mismos. José Maria Boquera Oliver, "La revocación de las licencias municipales”, Revista de Derecho Público $5^{8}$ (1975): 155 .

25 Ver supra nota 2I, 87.

26 Diego José Vera Jurado, La disciplina ambiental de las actividades industriales: autorizaciones y sanciones administrativas en materia de medio ambiente (Madrid: Servicio de Publicaciones e Intercambio Científico de la Universidad, D.L.,I994), I\&工.

27 Tomas-Ramón Fernández Rodríguez, El medio ambiente urbano y las vecindades industriales (Madrid: Instituto de Estudios de Administración Local, I973), ır6.

28 Ibid., II2. 
mentan una permanente modificabilidad corresponden a los estándares de contaminación, entendiendo por ello a aquellos umbrales o límites generales de permisibilidad en función de la capacidad de absorción que posee el medio receptor en el que se desarrolla una actividad ${ }^{29}$.

Cabe tener en cuenta que el control dinámico de la legalidad de la RCA recién descrito no corresponde sólo a un planteamiento teórico en base a la doctrina extranjera y nacional, sino que nuestro propio ordenamiento jurídico establece una serie de mecanismos destinados a prevenir la pérdida sobreviniente de los presupuestos de hecho de la RCA. Esto finalmente implica un reconocimiento de su naturaleza jurídica en cuanto a una autorización de funcionamiento, que posee la aptitud de regular en el tiempo el desarrollo de una actividad, y en donde la producción de sus efectos se despliega en el tiempo en paralelo a la permanencia del acto en el mundo jurídico. Así se constituye un fenómeno unitario, en donde no es posible disociar el acto de sus efectos ${ }^{30}$.

Por antonomasia, desde la dictación de la LBGMA, ha sido su artículo 8 -la norma que ha exigido la permanencia del presupuesto de hecho-que motivó el otorgamiento de la autorización, al imponer la obligación de ingresar al SEIA cualquier modificación de consideración que experimente el proyecto. Aun cuando el particular tiene el derecho a ejecutar el proyecto en los términos en que ha sido autorizado, si pretende modificar la actividad, deberá solicitar una nueva autorización para efectos de que la administración compruebe su adecuación con la normativa vigente y, en su caso, pueda imponer las medidas necesarias para hacerse cargo de los nuevos impactos que se generarán.

En el mismo sentido, destaca el artículo 25 ter de la LBGMA que impone un verdadero deber de ejecutar la actividad autorizada, pues de no darse inicio a ésta en el plazo dispuesto, se detonan los efectos de la caducidad, precisamente con el objeto de resguardar que el acto administrativo autorizatorio no pierda con el transcurso del tiempo su concordancia con el supuesto de hecho que le sirvió de fundamento.

Aún más explícita es la consagración de la facultad de revisión de la RCA en el artículo 25 quinquies de la LBGMA, la cual es procedente cuando, ejecutándose el proyecto, las variables evaluadas y contempladas en el plan de seguimiento sobre las cuales fueron establecidas las condiciones o medidas de un EIA, hayan variado sustantivamente en relación a lo proyectado o no se hayan verificado. Es decir, se trata del reconocimiento expreso de la acción de "volver a ver" el acto ${ }^{31}$, que implica contrastar de nuevo sus presupuestos de hecho y de derecho.

29 Ver supra nota 26, I4工

30 Tomas Cano Campos, La invalidez sobrevenida de los actos administrativos (Madrid: Civitas, 2004), 239 .

31 Landelino Lavilla Alsina, "La revisión de oficio de los actos administrativos", Revista de Administración Pública 34 (I961): 54-55. 
Es importante relevar que la procedencia de dicho mecanismo no se encuentra restringida a una oportunidad en particular, sino que éste puede ser gatillado durante toda la vigencia de la RCA en caso que se verifique una variación sustantiva de las variables ambientales evaluadas. De esta forma, aun cuando el procedimiento de revisión en análisis posea un ámbito específico, su consagración normativa constituye el requerimiento expreso de nuestro ordenamiento jurídico de la permanencia de los presupuestos de hecho de la $\mathrm{RCA}^{32}$, así como denota que dicho acto autorizatorio es un fenómeno unitario, toda vez que con posterioridad a su dictación es factible modificar su contenido y ajustarlo en razón de consideraciones de carácter preventivo que persiguen garantizar la no generación de riesgos y daños ambientales.

Es más, la redacción original del precepto en cuestión en el Mensaje de la Ley No 20.417, disponía que la RCA podía ser revisada cuando, ejecutándose el proyecto, los hechos sobre los cuales fueron establecidas las condiciones o medidas hubieran variado sustantivamente o éstos no se hubieran verificado. En dicho sentido el artículo rezaba: «La Resolución de Calificación Ambiental podrá ser revisada de oficio o a petición del titular, cuando ejecutándose el proyecto, los hechos sobre los cuales fueron establecidas las condiciones o medidas, han variado sustantivamente o estos no se han verificado [...]».

Lo expuesto evidencia que ya no se trata sólo de condicionar la autorización al mantenimiento de las circunstancias y motivos que justificaron su otorgamiento, sino que, si éstas cambian, no es posible tolerar dicha disconformidad, propendiéndose a su modificación para prevenir su retiro del mundo del Derecho.

En relación con lo planteado, conviene tener en cuenta que fue la doctrina italiana la que advirtió que los actos administrativos debían cesar en sus efectos cuando desaparecía la norma objetiva que les servía de sustento. Así, el cambio de una ley por otra producía la muerte del decreto que la reglamentaba, y la derogación del reglamento quitaba contenido jurídico a determinados actos generados en virtud de sus normas. De este modo, se dijo que los actos administrativos se extinguían por abrogación de las normas que los rigen ${ }^{33}$.

De igual modo, conviene relevar que el supuesto de cambio normativo también ha sido tratado como una causal de decaimiento ${ }^{34}$, entendiendo por esta figura extintiva a la ce-

32 Doris Sepúlveda Solar, "La facultad de revisión de la Resolución de Calificación Ambiental y la existencia de una potestad de invalidación implícita”, Revista de Derecho Administrativo 6 (2012): $5^{6 .}$

Eduardo Soto Kloss, "El cambio de circunstancias como causa de modificación o extinción del acto administrativo en el Derecho francés”, Revista de Administración Pública 64 (I971): 59-60

34 El profesor Enrique Silva Cimma creía innecesario configurar una nueva figura extintiva intermedia entre la revocación y la invalidación, porque cuando el acto se extingue por la carencia 
sación definitiva de la eficacia del acto administrativo, cuando, por ejemplo, desaparece el objeto sobre el cual el acto proyecta sus efectos o los supuestos facticos que le servían de soporte ${ }^{35}$. En el primer caso, la substancia o contenido del acto decae por la ocurrencia de un hecho que hace imposible su eficacia. El acto decae por inútil. En el segundo caso, el acto decae porque sus efectos son violatorios del ordenamiento jurídico, esto es, el acto deviene ilegitimo ${ }^{36}$. Es este último caso el que interesa en el presente análisis toda vez que, al desaparecer el fundamento normativo, el acto cae sin que sea necesario un querer administrativo para extinguirlo.

En consecuencia, de estimarse que el cambio que experimenten las normas que forman parte del contenido del acto constituye un factor externo a la voluntad de la administración, implicará asumir que el acto autorizatorio deja de existir por configurarse un supuesto de decaimiento y que, dada la naturaleza de dicha figura, no requerirá ser declarado, operando de forma automática.

Por otra parte, se ha sostenido que el cambio normativo genera la inexigibilidad del mantenimiento de los efectos o de la relación jurídica instaurada por el acto, producto de una ilegitimidad sobreviniente que conducirá a su revocación ${ }^{37}$. Lo anterior responde al denominado principio de "contemporaneidad del acto y la invalidez", en virtud del cual un acto sólo puede ser objeto de una calificación jurídica negativa, como la invalidez, en el momento de su nacimiento o perfección, toda vez que el acto se considera como un quid instantáneo. Así, su invalidez sólo puede referirse al momento de su formación y no a uno posterior, pues en tal caso el acto ya no está, no existe para el Derecho y, por tanto, no puede ser objeto de calificación jurídica alguna ${ }^{38}$. Sin embargo, desde nuestra

de un presupuesto de hecho, como, por ejemplo, la desaparición por causa de terremoto de un terreno de playa, que deja sin contenido jurídico a un acto de concesión sobre dicha playa, se produce la inutilidad de dicho acto, en cuyo caso el pronunciamiento de la administración se extingue por sí mismo. Así, cuando falta el presupuesto de derecho, se produciría una ilegitimidad sobreviniente que obligaría a la propia administración a invalidar el acto. Enrique Silva Cimma, "El acto administrativo y lo contencioso administrativo" (Curso de post graduados, ig60).

Luis Cordero Vega, Lecciones de derecho administrativo (Santiago: Thomson Reuters, 20I5), 3०2-3०3.

Hernán Olguín Juárez, Extinción de los actos administrativos revocación, invalidación y decaimiento (Santiago: Editorial Jurídica de Chile, I961), 269-270.

37 En consecuencia, el cambio normativo no determina la invalidez del acto, sino la ilegalidad sobrevenida de la situación jurídica a que ha dado lugar, es decir, la inexigibilidad del mantenimiento de los efectos o de la relación jurídica instaurada por el acto. Ver supra nota 5,33 I.

38 Ver supra nota $30,7^{\mathrm{I}}-75$. 
perspectiva, el desajuste que se pueda verificar entre el contenido de la RCA y la nueva regulación ambiental, constituye un supuesto de invalidez sobrevenida ${ }^{39}$.

Lo anterior está dado en atención a que se está en presencia de una autorización de funcionamiento, la cual - como ya se ha señalado - no se extingue con posterioridad a su dictación, sino que permanece en paralelo a la generación de sus efectos ${ }^{40}$. Así como por el hecho de que nuestro ordenamiento jurídico requiere la permanencia de los supuestos de hecho y de derecho que concurrieron al momento del otorgamiento de la RCA, al admitir, principalmente en el artículo 25 quinquies de la LBGMA, que su conformidad respecto de lo aprobado sea susceptible de ser revisada. De verificarse un cambio en el comportamiento de las variables ambientales y, en consecuencia, ser inconsistente el contenido de la RCA con aquéllas - al no considerar medidas adecuadas para hacerse cargo de los nuevos impactos ambientales- nuestro ordenamiento jurídico está reconociendo la necesidad de modificar y adecuar el acto autorizatorio a las circunstancias que se verifiquen con posterioridad a la dictación del acto.

De esta forma, considerando que es el contenido del acto aquél que tiene por objeto producir los efectos jurídicos del mismo, el mantener un contenido obligatorio que ya no se condice con la realidad resulta contrario al interés público que subyace al ejercicio de la potestad de evaluación ambiental, y que conforme al artículo 16 de la LBGMA requiere que las medidas ambientales se hagan cargo de los impactos.

En dicho sentido, pretender congelar el contenido de la RCA en lo que se refiere a los aspectos normados - en atención a un mero carácter certificatorio del acto autorizatorio como si éste generase efectos de forma instantánea- es del todo inconsistente con su naturaleza jurídica y las facultades de revisión antes mencionadas, cuando el cambio normativo constituye también una circunstancia sobreviniente que afectará el contenido de la RCA con posterioridad a su dictación, y que generará que los efectos del acto no se condigan con la nueva realidad a la cual atienda el respectivo cambio de la normativa ambiental.

39 Hemos criticado esta distinción entre invalidación y revocación por carecer de lógica (ya que la segunda no viene a ser sino una antijuricidad sobreviniente del acto administrativo por cambio de circunstancias, sean de hecho o de derecho). Eduardo Soto Kloss, "Invalidación de los actos administrativos", Revista Chilena de Derecho I6, n 2 (I989): 477 .

40 El profesor Luis Cordero, respecto del otorgamiento de la RCA, plantea que "no se agota el vínculo entre la autoridad administrativa (ambiental) y el solicitante, perdurando éste último por un período indeterminado de tiempo. Lo anterior, responde a la realidad de que la RCA se otorga en consideración a una situación de hecho concreta que es evaluada sobre la base de la normativa ambiental aplicable. De esta manera, y si durante el desarrollo del proyecto o actividad determinado llegaren a cambiar los supuestos de hecho que sirvieron de base para la RCA, puede llegar a configurarse un genuino problema de validez respecto del acto administrativo en cuestión, pero además justifica los poderes de revisión permanente de la administración como lo ha permitido la jurisprudencia administrativa”. Ver supra nota 35, 228. 
De ahí que se estime necesario dinamizar el control del presupuesto de hecho que sirve de base para la dictación de la RCA en lo que se refiere a la verificación del cumplimiento de la normativa ambiental aplicable, para equipararlo con aquél referido a los aspectos no normados de la evaluación ambiental.

\section{La revisión de la RCA como herramienta para su actualización normativa}

El estimar que la pérdida de adecuación entre el contenido de la RCA y el ordenamiento jurídico vigente conlleva la pérdida de un elemento estructural del acto autorizatorio - es decir, tratar el fenómeno como un supuesto de invalidez sobrevenida-implica entender que ésta por sí misma carece de consecuencias jurídicas en nuestro ordenamiento jurídico, y que aquellas consecuencias sólo se generan una vez que se emite una declaración formal en dicho sentido por parte del órgano competente para ello ${ }^{41}$.

En razón de ello, es posible identificar un periodo de validez provisoria en atención a la presunción de legalidad de la que están investidos los actos administrativos ${ }^{42}$, que impide que éstos sean calificados como inválidos hasta que no sean anulados por quien tiene la competencia para ello, y con arreglo a las reglas procedimentales que el ordenamiento establezca ${ }^{43}$.

41 Desde una segunda perspectiva, la nulidad es vista como una reacción ante la legalidad, consistente en la atribución al acto (con posterioridad a la ejecución de un específico test) de la propiedad de ser inhábil para producir efectos o eficacia jurídica. La nulidad no es ya una inqualificazione, sino más bien una qualificazione negativa del acto jurídico, en el sentido que se reconoce (jurídicamente) un acto normativo al cual, pese a ello, se le priva de sus efectos. Esta idea de nulidad es la que utilizamos normalmente en materia de control de actos normativos, en tanto reconocemos un acto al cual sometemos a un control de legalidad para luego concluir su nulidad que es el resultado de dicho juicio de legalidad. Raúl Letelier Wartenerg, Nulidad y restablecimiento en procesos contra normas, (Pamplona: Civitas-Thomson Reuters, 20II), 9I.

42 "Con la entrada en vigor de la LBPA, los actos administrativos son legales mientras no se diga lo contrario por el juez o por la propia Administración del Estado en un procedimiento que tenga como resultado su invalidación (art. 53 LBPA). Esta presunción de legalidad del acto administrativo permite su ejecución desde luego por la propia Administración Pública en uso de sus poderes de autotutela". Jorge Bermudez Soto, "Estado Actual del Control de Legalidad de los Actos Administrativos. ¿Qué queda de la Nulidad de Derecho Público?”, Revista de Derecho $23, \mathrm{n}^{\circ} \mathrm{I}(2010)$ : 107 .

43 La institución de la invalidación administrativa, al igual que la nulidad judicial, debe entenderse a la luz de la presunción de legalidad de la que están investidos los actos administrativos. Una vez notificados y publicados, el sistema jurídico otorga legitimidad, estabilidad y eficacia a los actos administrativos, los que producirán efectos mientras no sean impugnados o, más precisamente, mientras la impugnación no sea acogida por una autoridad competente. Es destinatario, o los afectados de un acto administrativo tienen, en consecuencia, la carga de impugnarlo si desean privarle de eficacia. Ver supra nota 35, 292. 
En atención a dicho contexto, se considera oportuno establecer un mecanismo de revisión de la RCA para verificar la concordancia de dicho acto con el ordenamiento vigente ${ }^{44}$, como una categoría intermedia entre la modificación stricto sensu $u^{25}$ y la extinción lisa y llana del acto, que permita la inclusión de nuevas cláusulas para adaptar el proyecto al nuevo escenario normativo. Tal como acontece en la legislación española, en donde, por ejemplo, el artículo 21 de la Ley 10/1991, de 4 de abril, para la protección el medio ambiente, dispone: «[p]or razón de la normativa ambiental o sectorial vigente en cada momento podrá exigirse la modificación o ampliación de las medidas correctoras o protectoras inicialmente establecidas». En la misma línea, el art. 39 de la Ley 11/2003, de 8 abril de Prevención Ambiental de Castilla y León, prevé que las autorizaciones ambientales se otorgan por un plazo máximo de ocho años, transcurrido el cual deberán ser renovadas y, en su caso, actualizadas por periodos sucesivos.

Al respecto, cabe tener en cuenta que la modificación del acto, producto de la inclusión de nuevas cláusulas o el reemplazo de las existentes, para efectos de ajustarlo al nuevo marco normativo, conllevará la extinción parcial del mismo y la creación de un nuevo acto en la parte modificada ${ }^{46}$.

En dicho sentido se sostiene que, si la corrección del defecto implica una modificación del contenido del acto administrativo, la eliminación del vicio conllevará la anulación de este acto o por lo menos una parte del mismo, ya que toda modificación del contenido de un acto administrativo supone dictar un acto administrativo distinto del que se dictó, lo que, con carácter general, sólo se puede lograr mediante su anulación; por el contrario, si el defecto se corrige sin afectar al contenido del acto, al haber corregido el vicio sin tener que anular ninguna parte del mismo, este se habrá convalidado ${ }^{27}$.

Ahora bien, el hecho de que la RCA sea un acto susceptible de ser divido en atención a su estructura de compartimientos estancos, definidos en atención a cada componente

44. Resulta evidente la utilidad que reviste la revisión del acto autorizatorio cuando está prevista como instrumento al servicio del control de la legalidad del mismo, pues ésta tendrá por objeto prevenir la extinción del acto administrativo, ajustando precisamente el contenido normativo de éste último al ordenamiento jurídico. Ver supra nota $3^{2}, 5^{6}$.

45 Otras figuras extintivas como el cambio de un acto por otro, esto es, su modificación. La modificación difiere de la revocación porque el nuevo acto tiene un contenido variable; en cambio, el acto revocatorio siempre está destinado a dejar sin efecto otro acto. Ver supra nota 2I, 5I.

46 La inclusión o modificación de cláusulas accesorias del acto, como consecuencia de cambio normativo, son supuestos de revocación parcial. Ver supra nota 7, 274

47 Margarita Beladiez Rojo, Validez y eficacia de los actos administrativos, (Madrid: Marcial Pons, I994), 205. 
ambiental objeto de evaluación, admite su invalidación parcial, más aún cuando la parte no viciada no depende de elementos que sólo posea la parte viciada ${ }^{48}$. Es decir, es factible que, aun cuando parte del contenido de la RCA sea invalido, aquella parte válida pueda cumplir autónomamente el fin que dicho acto pretende alcanzar, al menos para algún componente ambiental. En la actualidad esto acontece con el procedimiento establecido en el artículo 25 quinquies de la LBGMA, que permite la revisión de una parte del contenido de la RCA, correspondiente a aquélla referida exclusivamente a las variables ambientales que experimentan un cambio respecto de lo evaluado.

Lo planteado, además de ser consistente con nuestro ordenamiento jurídico, garantiza que la RCA en todo momento indique con precisión cuál es la situación jurídica de su titular, para efectos de anudar al mismo consecuencias jurídicas de forma sólida y segura ${ }^{29}$.

De esta forma, cuando el artículo 64 de la LBGMA dispone que la fiscalización que le corresponderá a la SMA será el permanente cumplimiento de las normas y condiciones sobre la base de las cuales se han aprobado o aceptado los Estudios y Declaraciones de Impacto Ambiental, debe entenderse que ello es bajo el supuesto de que el acto sea válido, es decir, que dichas normas y condiciones que sirvieron de base a la dictación de la respectiva RCA continúan ajustándose a la realidad normativa y fáctica, o que, en caso de que se haya verificado dicho desajuste, se haya emitido un nuevo acto autorizatorio que incorpore el cambio normativo.

\section{CONCLUSIÓN}

El control dinámico de la legalidad de la RCA surge como un imperativo de nuestro propio ordenamiento jurídico, el cual reconoce y consagra una serie de mecanismos destinados a prevenir la pérdida sobreviniente de los elementos estructurales de dicho acto autorizatorio.

Ante un escenario de cambio normativo, aun cuando la cesación de la vigencia de una norma no requiere de declaración alguna, la verificación de la compatibilidad del contenido del acto existente con los nuevos estándares ambientales, así como su eventual adaptación, requerirá necesariamente de un nuevo acto de carácter decisorio que modifique el primero. De ahí que urja la formalización de un procedimiento de revisión que permita flexibilizar en dicho sentido la RCA. $\square$

48 En dicho sentido, la STC del Segundo Tribunal Ambiental de 8 de febrero de 20I9, rol I4 ${ }^{\mathrm{I}-20 \mathrm{I}} 7$ (acumulada rol $\mathrm{R}_{4}{ }^{2-20 I 7}$ ).

49 Ver supra nota $7,28_{5}$. 


\section{BIBLIOGRAFÍA}

- Barros Bordeu, Alberto. "Regulación y discrecionalidad en el sistema de evaluación de impacto ambiental: el procedimiento administrativo como garantía procedimental". Tesis de pregrado. Universidad de Chile, 2009.

- Beladiez Rojo, Margarita. Validez y eficacia de los actos administrativos. Madrid: Marcial Pons, 1994.

- Bermúdez Soto, Jorge. Fundamentos de Derecho Ambiental. Valparaíso: Ediciones Universitarias de Valparaíso, 2014.

- __Estado Actual del Control de Legalidad de los Actos Administrativos. ¿Qué queda de la Nulidad de Derecho Público?" Revista de Derecho 23, nº1 (2010): 103-123.

- Boquera Oliver, José María. "La revocación de las licencias municipales”. Revista de Derecho Público 58 (1975):147-178.

- Cano Campos, Tomás. La invalidez sobrevenida de los actos administrativos. Madrid: Civitas, 2004.

- _El "El laberinto de la invalidez: algunas pistas para no perderse”. Revista para el Análisis del Derecho, n 4 (2017): 1-42.

- Carrasco Quiroga, Edesio y Javier Herrera Valverde. "La interpretación de la Resolución de Calificación Ambiental”. Revista Chilena de Derecho 41, nº (2014): 635-671.

- Carretero Pérez, Adolfo. "Causa, motivo y fin del acto administrativo”. Revista de Administración Pública 58 (1969): 127-147.

- Chinchilla Marín, Carmen. La desviación de poder. Madrid: Civitas, 1999.

- Cordero Vega, Luis. Lecciones de derecho administrativo. Santiago: Thomson Reuters, 2015.

- Diez, Manuel María. El acto administrativo. Buenos Aires: Editora Argentina S.A., 1961.

- Díez-Picazo, Luis María. La derogación de las leyes. Madrid: Civitas, 1990. 
- Fermandois, Arturo. "Invalidación Administrativa y caso Celco: estabilidad o precariedad de los permisos ambientales”. Sentencias Destacadas, 9-30. Santiago: Libertad y Desarrollo, 2005.

- Fernández Rodríguez, Tomas-Ramón. El medio ambiente urbano y las vecindades industriales. Madrid: Instituto de Estudios de Administración Local, 1973.

- Galindo Villarroel, Mario. "Concepto de la RCA y jurisprudencia relacionada”. Presentación en IV Seminario: La Resolución de Calificación Ambiental (RCA): su real naturaleza y sus consecuencias, Universidad de los Andes, 2006.

- Guzmán, Felipe, "Algunos aspectos de la relación entre la RCA y normativa vigente". Presentación en IV Seminario: La Resolución de Calificación Ambiental (RCA): su real naturaleza y sus consecuencias, Universidad de los Andes, 2006

- Laguna De Paz, José Carlos. La autorización administrativa. Madrid: Civitas-Thomson Reuters, 2006.

- Landelino Lavilla Alsina. "La revisión de oficio de los actos administrativos”. Revista de Administración Pública 34 (1961): 53-98.

- Letelier Wartenerg, Raúl. Nulidad y restablecimiento en procesos contra normas. Civitas-Thomson Reuters, 2011.

- Mardones Osorio, Marcelo y Nicolás Cannoni Mandujano. "Caducidad de la Resolución de Calificación Ambiental y Reglamento del SEIA". Revista Chilena de Derecho 43, 2 (2016): 573-600.

- Olguín Juárez, Hernán. Extinción de los actos administrativos revocación, invalidación y decaimiento. Santiago: Editorial Jurídica de Chile, 1961.

- Piccinini García, Doris. Teoría del decaimiento de los actos administrativos. Santiago: Editorial Jurídica de Chile, 1968.

- Sepúlveda Solar, Doris. "La facultad de revisión de la Resolución de Calificación Ambiental y la existencia de una potestad de invalidación implícita", Revista de Derecho Administrativo 6 (2012): 47-62.

- Silva Cimma, Enrique. "El acto administrativo y lo contencioso administrativo". Curso de post graduados, 1960.

- Soto Kloss, Eduardo. "Invalidación de los actos administrativos". Revista Chilena de Derecho 16, $\mathrm{n}^{\circ} 2$ (1989): 475-488. 
- ___ "El cambio de circunstancias como causa de modificación o extinción del acto administrativo en el Derecho francés". Revista de Administración Pública 64 (1971):53-105.

- Urrutia Cáceres, Juan Iǵnacio. "El impacto ambiental no previsto en el marco del Sistema de Evaluación de Impacto Ambiental”. Tesis de magíster. Universidad de Chile, 2009,

- Velasco Caballero, Francisco. Las cláusulas accesorias del acto administrativo. Madrid: Tecnos, 1996.

- Vera Jurado, Diego José. La disciplina ambiental de las actividades industriales: autorizaciones y sanciones administrativas en materia de medio ambiente. Madrid: Servicio de Publicaciones e Intercambio Científico de la Universidad, D.L.,1994. 